\title{
Risk Factors for Postoperative Delirium After Cardiac Surgery at the Clinical Center of Montenegro
}

\author{
Dragica Dobrovic ${ }^{1,2}$, Damir Pelicic ${ }^{1,2 *}$ and Mitar Saveljic ${ }^{1,2}$ \\ ${ }^{1}$ Clinical Center of Montenegro, Podgorica, Montenegro \\ ${ }^{2}$ Faculty of Medicine, University of Montenegro, Podgiorica Montenegro \\ *Corresponding author: Damir Pelicic, Clinical Center of Montenegro, Podgorica, Montenegro
}

\section{ARTICLE INFO}

Received: 㓞 November 18, 2020

Published: 㗀 November 24, 2020

Citation: Dragica Dobrovic, Damir Pelicic, Mitar Saveljic. Risk Factors for Postoperative Delirium After Cardiac Surgery at the Clinical Center of Montenegro. Biomed J Sci \& Tech Res 32(1)-2020. BJSTR. MS.ID.005203.

Keywords: Delirium; Intensive Care Unit; Cardiac Surgery Operation

\section{ABSTRACT}

Introduction: Postoperative delirium in the Intensive Care Unit (ICI) is a common complication after cardiac-surgery and is linked to increased morbidity and mortality. Pathophysiology and etiology of delirium are unknown, and the onset of delirium in each patient is caused by interactions of predisposed and other factors.

Research Goals: To identify the occurrence of postoperative delirium and analysing the reasons for onset of delirium: the length of hospitalization, the length of surgical procedure and extracorporeal circulation, the length of intubation, length of stay in ICI, incidence of postoperative complications (disturbance in AF, VF) as well as presence of alcohol and nicotine consumption. Based on research detect the reasons for onset of postoperative delirium in cardiac patients in Clinical Center of Montenegro.

Results: Statistically relevant predictors of onset of delirium after cardiac-surgery were: length of extracorporeal circulation, length of hospitalization in ISI, disturbances of heart rhythm and prolonged intubation.

Conclusion: Longer patient-stay at the Intensive Care Unit after cardiac surgery operation influences the onset of delirium.

\section{Introduction}

Introduction Delirium is one of the oldest forms of mental disorders known in medical history, then characterized as an "acute confusion condition." In everyday use, nowadays, it means drowsiness, disorientation and the presence of hallucinations. However, in medical terminology, there are many other symptoms, including a sudden loss of the ability to focus attention, and even occasional drowsiness and severe agitation and irritability. In the countries of the European Union, cardiovascular mortality was $42 \%$ and in Montenegro in 2008 it was 54\%. In Montenegro, in the last six years, there is a growing trend in the number of patients with cardiovascular diseases and their presence as a group in total deaths [1]. High participation of cardiovascular and malignant diseases in the structure of mortality reflects the present risky behavior in the population, such as smoking, alcoholism, improper diet, insufficient physical activity, but also the effect of environmental risk factors: air pollution, unhealthy diet, poor socio-economic living conditions etc. [2-6]. Postoperative delirium in the Intensive
Care Unit (ICU) is a common complication after cardiac surgery and is associated with increased morbidity and mortality. However, in medical terminology, there are many other symptoms, including a sudden loss of the ability to focus attention, and even occasional drowsiness and severe agitation and irritability.

The definition of delirium is that it is a state of acute weakening of attention-focus, perception, power of comprehension that leads to various forms of semi-consciousness; that it is a syndrome caused by organ damage (by disease or chemically) and causes disruption (destruction) of neurons of the cerebellar cortex [7]. Delirium is not a disease, but a clinical syndrome of the underlying disease or a syndrome of emerging problems in the cognitive sphere; it is simply the most common symptomatic manifestation of early brain or mental dysfunction (caused by any reason) [8]. After surgery in the ICU, and after extubation, cardiac surgery patients in a number of cases enter a state of mental confusion and disorientation in time, space, towards themselves and towards others [9]. The incidence 
of delirium in the surgical intensive care unit is higher than $30 \%$. In intubated patients, the incidence of delirium increases to $80 \%$ [10]. The incidence of delirium in septic patients ranges from a very wide range of $9 \%$ to $71 \%$. Patients on mechanical ventilation who developed delirium have a significantly higher 6-month mortality compared with patients on mechanical ventilation who did not develop delirium [11].

\section{Research Goals}

Determine the total number of patients with postoperative delirium in the ICU. Treatments, Center for Cardiac Surgery of the Clinical Center of Montenegro. Determine the average duration of extracorporeal circulation of these patients; Determine the length of postoperative hospitalization of these patients in the ICU, the Center for Cardiac Surgery, the Clinical Center of Montenegro; Determine the prevalence of intraoperative and postoperative complications (polytransfusion, emergency surgery, prolonged intubation, cardiac arrhythmia: AF, VF) Based on the research, detect the reasons for the occurrence of postoperative delirium in cardiac surgery patients at the Clinical Center of Montenegro. Patients and research methods Patient's Postoperative delirium occurred in 52 patients (study group), and 298 patients did not have postoperative delirium (control group).

Criteria for inclusion of patients in the study: Patients of both sexes who had cardiac surgery at the Center for Cardiac Surgery of Montenegro

1. Patients who agreed to participate in the study. Criteria for excluding patients from the study:

2. Patients who did not agree to participate in the study.

\section{Research Methods}

The study is retrospective, descriptive and clinical. The method of work in the research was a retrospective analysis of medical histories and lists of intensive care of operated patients in the mentioned period. The processing of the obtained data was done in IBM SPSS - 17 program for statistical data processing. The obtained data are presented as a percentage share of individual phenomena in both groups and statistical significance is shown. The results of the research are presented in a table. Statistical processing of results Primarily obtained data were analyzed by descriptive statistical methods and hypothesis testing methods. To test the frequency difference of the variable categories, use the Pearsonsquare test, the Fisher test of the exact probability, and to test the difference for the numerical variables, the MannWhitney test. The logistic regression model was used to examine possible predictors of delirium as a dependent variable. The Hosmer Lemeshow test was used to assess the similarity of the model. Conclusion was performed at a significance level of 0.05 . The data were processed in the statistical program for social sciences SPSS 17.

\section{Results}

Number of patients with postoperative delirium in the Intensive Care Unit of the Center for Cardiac Surgery, Clinical Center of Montenegro in the period from 01.01.2014. until 31.12.2014 it amounted to 52 which is $14.86 \%$ of all operated patients in this unit (Table 1). The median duration of surgery in patients who did not develop delirium was 240 minutes (range 150-465), and in the group in which it was 240 minutes (range 150-480). There is no statistically significant difference in the duration of surgery between these two groups of patients ( $U=7459.0$; $p=0.666$ ) (Table 2). The median duration of CEC in the group of patients without delirium was $67(0-285)$, and in patients with delirium it was $72.50(0-216)$. The onset of delirium was preceded by a statistically significantly longer duration of CEC $(U=6248 ; p=$ 0.026) (Table 3). The average length of hospitalization in relation to the occurrence of postoperative delirium. The average length of hospitalization in the Intensive Care Unit in patients without delirium is $3.89 \pm 2.15$ days, and in patients with delirium it is 5.71 \pm 4.34. Statistically significantly longer hospitalization preceded the occurrence of delirium ( $U=5415.0 ; p<0.001$ ) (Table 4). Logistic regression examined the relationship between gender, age, duration of surgery, duration of extracorporeal circulation, length of hospitalization, alcohol consumption, tobacco, drugs, and the presence of psychiatric diagnosis and intraoperative and postoperative complications as independent variables on delirium as a dependent variable in patients operated on. The cymodel, with the entered variables, which showed as a statistically significant predictor in the univariate analysis, was statistically significant $(7$ variables entered into the model, $\mathrm{N}=350$ ) $=125.715, \mathrm{p}<0.001$, Hosmer $=0.627$. The model as a whole explains $30.2 \%$ (according to Cox and Snell) $-53.1 \%$ (according to Nagelkerke) of variability in delirium status, and accurately classifies $88.6 \%$ of cases. As shown in Table 5, statistically significant predictors of delirium were shown: length of hospitalization, heart rhythm disorders, polytransfusion, prolonged intubation A person is more likely to have delirium if he is hospitalized longer ( $K V=1.218$; 95\% IP: 1.063 - 1,395), if she had a heart rhythm disorder (KV = 4,578; $95 \%$ IP: 2,040-10,276), if she did not have polytransfusion (KV = .174; 95\% IP: .051- .595), if she had a prolonged intubation (KV= 22.130; 95\% IP: 8.009- 61.147) (Table 5).

Table 1: Analysis of data on the number of patients with postoperative delirium.

\begin{tabular}{|c|c|}
\hline Group & Number of Patients (\%) \\
\hline Control group & $298(85,14 \%)$ \\
\hline Study group & $52(14,86 \%)$ \\
\hline Total operated patients & $350(100)$ \\
\hline
\end{tabular}


Table 2: Analysis of the duration of the operation in relation to the occurrence of postoperative delirium

\begin{tabular}{|l|c|c|c|c|c|}
\hline \multirow{2}{*}{} & \multicolumn{4}{|c|}{ Postoperative Delirium } & \multirow{2}{*}{$\begin{array}{c}\text { The value of the } \\
\text { Mann Whitney U test }\end{array}$} \\
\cline { 2 - 6 } & \multicolumn{2}{|c|}{ Control group } & Study group & \\
\cline { 2 - 6 } & Mean value \pm sd & Median (range) & Mean value \pm sd & Median (range) & \\
\hline Operation length (min) & $246,14 \pm 64,40$ & $240(150-465)$ & $247,69 \pm 63,33$ & $240(150-480)$ & 7459 \\
\hline
\end{tabular}

Table 3: Analysis of the duration of extracorporeal circulation (CEC) in relation to the occurrence of postoperative delirium.

\begin{tabular}{|c|c|c|c|c|c|c|}
\hline & \multicolumn{4}{|c|}{ Postoperative delirium } & \multirow{3}{*}{$\begin{array}{c}\text { The value of the Mann } \\
\text { Whitney } U \text { test }\end{array}$} & \multirow{3}{*}{$\mathbf{p}$} \\
\hline & \multicolumn{2}{|c|}{ Control group } & \multicolumn{2}{|c|}{ Study group } & & \\
\hline & Mean value \pm sd & Median (range) & Mean value \pm sd & Median (range) & & \\
\hline CEC duration (min) & $69,85 \pm 24,44$ & $67(0-285)$ & $81,17 \pm 38,76$ & $72,50(0-216)$ & 6248 & 0,026 \\
\hline
\end{tabular}

Table 4: Analysis of the length of hospitalization in the Intensive Care Unit in relation to the occurrence of postoperative delirium.

\begin{tabular}{|c|c|c|c|c|c|}
\hline \multirow{2}{*}{} & \multicolumn{4}{|c|}{ Postoperative Delirium } & \multirow{2}{*}{$\begin{array}{c}\text { The value of the Mann } \\
\text { Whitney U test }\end{array}$} \\
\cline { 2 - 5 } & \multicolumn{2}{|c|}{ Control group } & \multicolumn{2}{c|}{ Study group } & Median (range) \\
\cline { 2 - 5 } & Mean value \pm sd & Median (range) & Mean value \pm sd & $4(2-22)$ & 5415 \\
\hline $\begin{array}{c}\text { Length of hospitalization } \\
\text { (days) }\end{array}$ & $3,89 \pm 2,15$ & $4(0-14)$ & $5,71 \pm 4,34$ & 0,000 \\
\hline
\end{tabular}

Table 5: Results of examining the probability of delirium in patients operated on cardiac surgery using multiple logistic regression analysis

\begin{tabular}{|c|c|c|c|c|c|c|c|c|}
\hline & \multirow{2}{*}{ B } & \multirow{2}{*}{$\begin{array}{l}\text { Standard } \\
\text { error }\end{array}$} & \multirow{2}{*}{ Wald } & \multirow{2}{*}{$\begin{array}{l}\text { Degrees of } \\
\text { freedom }\end{array}$} & \multirow{2}{*}{$\mathbf{p}$} & \multirow{2}{*}{$\begin{array}{l}\text { Probability } \\
\text { quotient }\end{array}$} & \multicolumn{2}{|c|}{$\begin{array}{l}95 \% \text { confidence interval from the } \\
\text { probability quotient }\end{array}$} \\
\hline & & & & & & & Lower limit & Upper limit \\
\hline Age & 0.009 & 0.022 & 0.156 & 1 & 0.693 & 1.009 & 0.966 & 1.054 \\
\hline Duration CECu min & 0.011 & 0.006 & 3.263 & 1 & 0.071 & 1.011 & 0.999 & 1.022 \\
\hline Length of hospitalization & 0.197 & 0.069 & 8.072 & 1 & 0.004 & 1.218 & 1.063 & 1.395 \\
\hline Heart rhythm disorders & 1.521 & 0.413 & 13.601 & 1 & 0 & 4.578 & 2.04 & 10.276 \\
\hline polytransfusion & -1.749 & 0.628 & 7.766 & 1 & 0.005 & 0.174 & 0.051 & 0.595 \\
\hline Prolonged intubation & 3.097 & 0.519 & 35.669 & 1 & 0 & 22.13 & 8.009 & 61.147 \\
\hline Smoking & 0.732 & 0.412 & 3.162 & 1 & 0.075 & 2.08 & 0.928 & 4.662 \\
\hline Constant & -5.237 & 1.638 & 10.228 & 1 & 0.001 & 0.005 & & \\
\hline
\end{tabular}

\section{Discussion}

The pathophysiology and etiology of delirium is unknown, and the onset of delirium in each individual patient is caused by the interaction of predisposing and other factors. The probability of developing delirium increases in proportion to the number of existing risk factors [12]. In addition to older age, pre-existing cognitive impairment is the most commonly confirmed independent risk factor for delirium in the literature. In our study, patients who developed delirium after heart surgery were statistically significantly older [13]. The prevalence and incidence of delirium in surgical patients is high. In cardiac surgery patients, delirium occurs in $23 \%$ to $32 \%$ of cases [14-17]. Delirium was diagnosed in $55 \%$ of patients, 70 years and older, who underwent heart surgery, which does not correlate with our research [18]. (Luders et al.) In 2012 , in one of the studies, they predicted postoperative delirium after heart surgery, placing the aspect of the research on the age structure of the patients on whom the research was performed
[19]. The incidence of delirium in selected works shows that the occurrence of delirium in cardiac surgery ranges from $3 \%$ to $52 \%$. The incidence is higher in hospitalized elderly patients by $25 \%$ [20]. Anesthesia, in itself, does not directly affect the onset of delirium after heart surgery, but inadequate oxygen supply to the brain, hydroelectrolyte imbalance, and patient awareness during surgery may contribute to this phenomenon. Delirium is a very common disorder in hospitalized elderly patients, with a prevalence of $10 \%$ to $30 \%$ and an incidence during hospitalization of $4 \%$ to $30 \%$.

The greatest contribution to the development of delirium from the examined variables is given by prolonged intubation, followed by heart rhythm disorders and the length of hospitalization. A patient who had, compared to a patient who did not have prolonged intubation, is 22.13 times more likely to get delirium. Patients who develop a heart rhythm disorder are almost 5 times more likely to develop delirium [21-23]. The authors believe that prior to the study, psychological assessment and psychiatric examination 
of patients were not included, and therefore psychiatric family history cannot be considered as a predictor that may influence the occurrence of delirium after surgery $[24,25]$. The age of the patient may be a key etiological factor for delirium. Comparative studies have shown that the incidence of postoperative delirium in patients> 65 years of age is 4-10 times higher than in the younger population and 3 times higher in patients $>75$ years of age than in patients $>65$ years of age [26]. It is evident that the frequency and prevalence of delirium in elderly patients is higher than in other age groups. In general, the incidence of delirium is assumed to be $25 \%$ in hospitalized elderly patients [27]. Research has shown that the effect of prevention to prevent delirium is very limited. Further studies on the prevention of delirium in patients with cardiac surgery are needed [28]. Delirium is easily underestimated in clinical practice. Taking into account all risk factors and potential complications, importance is given to improving the general health of patients, thus reducing the frequency and severity of delirium after heart surgery $[29,30]$.

\section{Conclusion}

We proved that age is a predictor of delirium in patients in the cardiac surgery department. Longer duration of extracorporeal circulation is a predictor of postoperative delirium after cardiac surgery. We concluded that patients who had delirium after cardiac surgery also had prolonged hospitalization. Statistically significantly longer hospitalization in the ICU preceded the occurrence of delirium. Prevalence of postoperative complications such as: heart rhythm disorder, prolonged intubation are significant predictors of delirium in our study, while re-surgery and polytransfusion have no statistically significant effect on the occurrence of delirium. In this paper, the working hypothesis that the length of hospitalization in the ICU affects the occurrence of delirium is confirmed, we also proved that longer hospitalization after cardiac surgery, affects the occurrence of delirium.

\section{Conflict of Interest}

The authors declare that there is no conflict of interest.

\section{References}

1. Nikolić G, Musić LJ, Knežević B, Vukmirović M (2012) Prevencija kardiovaskularnih bolesti. Podgorica p. 8-9.

2. Smultera S, Lingehalla HC, Gustafsonc Y, Olofssonb B, Engströma KG (2013) Delirium after cardiac surgery: incidence and risk factor. Interact CardiovascThorac Surg 17(5): 790-796.

3. Brooks M, Barclay L (2012) Delirium After Heart Surgery Prolonged Decline in Cognitive Function. Engl J Med 367: 30-39.

4. Whitlock EL, Torres BA, Lin N, Helsten DL, Nadelson MR, et al. (2014) Postoperative delirium in a substudy of cardiothoracic surgical patients in the BAG-RECALL clinical trial. 118(4): 809-817.

5. Rudolph JL, Inouye SK, Jones RN, Jang FM, Fong TG, et al. (2010) Delirium: An Independent Predictor of Functional Decline After Cardiac Surgery. Journal of the American Societi 58(4): 643-649.
6. Kalezić N, Dimitrijević I, Leposavić Lj, Kočića M, Bumbaširević V, et al. (2006) Postoperative cognitive deficits. Serbian archive for all medicine 134(7-8): 331-338.

7. Koster S, Hensens A, Schuurmans M, Palen J (2013) Prediction of delirium after cardiac surgery and the use of a risk checklist. European journal of cardiovascular nursing 12(3): 284-292.

8. Escarain M, Cicolini A, Barbieri M, Renedo M, Falcon L, et al. (2013) Predictors of Delirium After Cardiac Surgery. Circulation 128: 22.

9. Bakker R, Osse R, Tulen J, Kappetein A, Bogers J (2012) Preoperative and operative predictors of delirium after cardiac surgery in elderly patients. European Journal of Cardio-Thoracic Surgery 41(3): 544-549.

10. Girard TD, Pandharipande PP, Ely EW (2008) Delirium in the intensive care unit. Crit Care 12: S3.

11. Ely EW, Shintani A, Truman B, Speroff T, Gordon SM, et al. (2004) Delirium as a predictor of mortality in mechanically ventilated patients in the intensive care unit. JAMA 291: 1753-1762.

12. Inouye SK, Bogardus Jr ST, Charpentier PA, Leo-Summers L, Acampora D, et al. (1999) A multicomponent intervention to prevent delirium in hospitalized older patients. N Engl J Med 340: 669-676.

13. Lin RY, Heacock LC, Bhargave GA, Fogel JF (2010) Clinical associations of delirium in hospitalized adult patients and the role of on admission presentation. Int J Geriatr Psychiatry 25: 1022-1029.

14. McCuster J, Cole M, Dendukuri N, Han L, Belzile É (2003) The Course of Delirium in Older Medical Inpatients: A Prospective Study. J Gen Intern Med 18: 696-704.

15. Mason SE, Noel-Storr A, Ritchie CW (2010) The impact of general and regional anesthesia on the incidence of post-operative cognitive dysfunction and post-operative delirium: a systematic review with meta-analysis. J Alzheimers Dis 22(3): 67-79.

16. Siddiqi N, House AO, Holmes JD (2006) Occurrence and outcome of delirium in medical in-patients: A systematic literature review. Age and Ageing 35: 350-364.

17. Packard RC (2001) Delirium. Neurologist 7: 327-340. 57. Lindesay J, Rockwood K, Rolfson D (2002) The epidemiology of delirium. In: Lindesay J, Rockwood K, Macdonald A (Eds.,). Delirium in old age. Oxford: Oxford University Press p. 27-50.58.

18. Eriksson M, Samuelsson E, Gustafson Y, Åberg T, Engström KG (2002) Delirium after coronary bypass surgery evaluated by the organic brain syndrome protocol. Scand Cardiovasc J 36: 250-255.

19. Lurdes TS, Schwartz SK, Bowering JB, Moore RL, Burns KD, et al. (2012) Pharmacological Risk Factors for Delirium after Cardiac Surgery: A Review. Current Neuropharmacology 10: 181-196.

20. Kazmierski J, Knowman M, Banch M, Fendler W, Okonski P (2010) Incidence and predictors of delirium after cardiac surgery: Results from the IPDACS Studey. J Psychosom Re 69: 179-185.

21. Koster S, Oosterveld FG, Hensens AG, Wijma A, van der Palen J (2008) Delirium after cardiac surgery and predictive validity of a risk checklist. Ann Thorac Surg 86: 1883-1887.

22. Kazmierski J, Kowman M, Banach M, Pawelczyk T, Okonski P, et al. (2006) Preoperative predictors of delirium after cardiac surgery: a preliminary study. Gen Hosp Psychiatry 28: 536-538.

23.van der Mast RC, van den Broek WW, Fekkes D, Pepplinkhuizen L, Habbema JD (1999) Incidence of and preoperative predictors for delirium after cardiac surgery. J Psychosom Res 46: 479-483.

24.van der Mast RC, van den Broek WW, Fekkes D, Pepplinkhuizen L, Habbema JD. Is delirium after cardiac surgery related to plasma amino acids and physical condition? J Neuropsychiatry Clin Neurosci 12: 57-63. 
25. Koster S, Oosterveld FG, Hensens AG, Wijma A, van der Palen J (2008) Delirium after cardiac surgery and predictive validity of a risk checklist. Ann Thorac Surg 86: 1883-1887.

26. Ruan J, Gao Y, Hang YN (2007) Central nervous system complications after general anesthesia. Chinese J Med Guide 9: 387-388.

27. ucerius J, Gummert JF, Borger MA, Walther T, Doll N, et al. (2004) Predictors of delirium after cardiac surgery delirium: effect of beatingheart (off-pump) surgery. J Thorac Cardiovasc Surg 127(1): 57-64.

28. Amberini M, Bolliger D, Lurati Buse GA, Burkhart CS, Grapow M, et al. (2009) Rivastigmine for the prevention of postoperative delirium in

ISSN: 2574-1241

DOI: $10.26717 / B J S T R .2020 .32 .005203$

Damir Pelicic. Biomed J Sci \& Tech Res

(C) This work is licensed under Creative

Submission Link: https://biomedres.us/submit-manuscript.php elderly patients undergoing elective cardiac surgery--a randomized controlled trial. Crit Care Med 37(5): 1762-1768.

29. Serruys PW, Morice MC, Kappetein AP, Colombo A, Holmes DR, et al. (2009) Percutaneous coronary intervention versus coronary-artery bypass grafting for severe coronary artery disease. N Engl J Med 360: 961-972.

30. McKhann GM, Grega MA, Borowicz LM, Bechamps M, Selnes OA, et al. (2012) Encephalopathy and stroke after coronary artery bypass grafting: incidence, consequences, and prediction. Arch Neurol 59: 1422-1428.

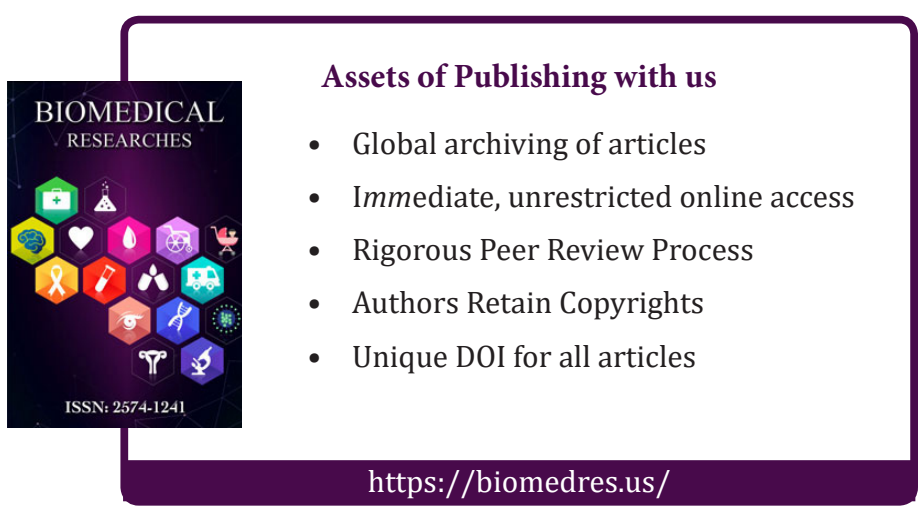

